\title{
Prevalence of Depression and Suicidal Thoughts amongst University Students in Poznan, Poland, Preliminary Report
}

\author{
Ewa Mojs, Katarzyna Warchol-Biederman, Wlodzimierz Samborski \\ Poznan University of Medical Sciences, Poznan, Poland \\ Email: ewamojs@ump.edu.pl
}

Received July $3^{\text {rd }}, 2011$; revised September $18^{\text {th }}, 2011$; accepted October $19^{\text {th }}, 2011$

\begin{abstract}
Objective: The goal of the study was to evaluate the prevalence of depression and suicidal thoughts in first year university students in Poznan, Poland and to assess whether they were connected with demographic factors such as age, having brothers or sisters, a specific social background or living arrangements, one's major and the mode of the study program. Method: 210 freshmen, who were 18 - 28 years old $(M=$ $19.81 ; S D=1.18$ ) anonymously answered a questionnaire on their perception of the risk of depression (KADS) and another demographics survey, including questions about age, having brothers/sisters, background, place of residence, living arrangements and their major (curriculum focus). Results: The analysis has shown that as many as 36 subjects $(17.1 \%)$ were at risk of depression and 18 of them $(8.6 \%)$ had suicidal thoughts. Among analyzed factors such as age, having brothers or sisters, social background, living arrangements, curriculum major and the mode of study, only the financial status was found to have a statistically significant influence on both susceptibility to depression and suicidal thoughts. Conclusion: It may be suggested that financial status most frequently influences depression in first year students but other agents leading to depression in students have not been clearly figured out or taken into account in screening tools for depression. So, further research is necessary to find out factors, which perhaps single-handedly or in connection with others, lead to or correlate with depression in college students.
\end{abstract}

Keywords: Depression; Suicide; Suicidal Thoughts; Student

\section{Introduction}

Suicide is the third leading cause of death in adolescence and young adulthood. Due to the fact that suicide rates in young people have continuously been increasing, its prevention remains one of the most important challenges for mental health research. Until now, several papers on youth suicide have been published. Literature shows that many psychological, epidemiological, socio-economic and psychiatric factors or processes may lead to suicide [1-5].

From psychological point of view, the influence of family life is essential because problems such as living amidst unresolved conflicts, loss of a parent, poor communication with parents or poor parental mental health status may mean a greater risk of suicide or suicide behavior. Additionally, reports indicate the impact of educational and economic disadvantage, perceived life's hardships, individual resilience to stress or interplay of these agents can also be significant. Recent findings point to the fact that self-inflicted death may be triggered by internet or media, which disseminate pro-suicide materials or websites (1-5).

Many reports indicate that depression is a significant agent leading to suicide. Based on literature, Cash et al. said that up to $60 \%$ of adolescent suicide victims had depression at the time of death. Furthermore, between $40 \%-80 \%$ of adolescents were clinically depressed at the time of suicide attempt [2]. Depression has also been linked with suicidal thoughts or suicidal ideation and tests such as Kutcher's KADS and M-BDI were used as screening tools to evaluate susceptibility to depression and suicidal thoughts in young people [6-8]. Because of an increase in suicide rates in Poland, the evaluation of prevalence of depression and factors influencing its onset in young people living in our country is becoming more and more important, not only from theoretical, but also from practical point of view $[2,8,14]$.

For many reasons particular interest should be paid to depression in first year university students. To begin with, first year at a university is a time of transition, a sudden change in the mode and organization of study. Additionally, starting college is often connected with leaving home, starting to live on one's own and new adult responsibilities. It may also mean attenuated connections with a family of origin, losing touch with one's network of social support and adaptation to a new social environment [14-18]. Until now, there have not been any studies devoted to this area of interest in Poland. Here, however, one should mention the study carried out by Mikolajczyk et al. [8], who assessed prevalence of depression in samples of first semester Polish, Danish, German and Bulgarian students. The study showed that female gender and perceived income insufficiency were associated with higher levels of depressive symptoms. Nevertheless, one should note that Polish students in this study were represented by participants from the Catholic University of Lublin, which is located in Eastern Poland. The province of Lublin differs economically, culturally and socially from most Polish provinces so the results of the study cannot be generalized to the entire population of Polish students.

Taking into account the importance and consequences of depression, especially in this age group, as well as current unsatisfactory state of knowledge concerning depression in freshmen students the aim of our study was to estimate susceptibility to 
depression and suicidal thoughts in freshmen students attending universities in Poznan, Wielkopolska. We selected the Midwestern Polish region of Wielkopolska because it is typical for most parts of Poland and similar to Western Europe. We also wanted to estimate whether the risk of depression and suicidal thoughts in first year students was connected with demographic factors such as age, having brothers or sisters, background, living arrangements, one's major and the mode of study.

\section{Material and Methods}

Study participants were 210 freshmen studying psychology $(n=135 ; 64.3 \%)$, midwifery $(n=52 ; 24.8 \%)$, physiotherapy $(n$ $=21 ; 10.0 \%)$, computer science $(n=1 ; .5 \%)$ and philosophy $(n$ $=1 ; .5 \%)$, who voluntarily and anonymously answered a questionnaire on the risk of depression (KADS) and a demographics survey including questions about participant's age, having brothers/sisters, background, place of residence, living arrangements and their major study area. They were $18-28$ years old $(M=19.81 ; S D=1.18)$. The study was carried out in two major universities: University of Medical Sciences and Adam Mickiewicz University in Poznan, Poland.

KADS (The Kutcher Adolescent Depression Scale), which is an extensively used self-report scale and a screening tool, designed for use in institutional settings to identify young people at risk of depression, consists of six statements on sadness, hopelessness, tiredness, difficulties of life, worry and suicidal thoughts. Subjects selected the most suitable answer on the 0 3 scale [ 0 - hardly ever, $1-$ much of the time, $2-$ most of the time, 3 - all of the time].

They were examined individually in conditions ensuring that their privacy and confidentiality were duly protected.

The test assumes anyone who scores six points and above is at a risk of depression. The internal consistency (Cronbach's $\alpha$ ) was $=84$ whereas the correlations between test items ranged from $=.35$ to $=.66$ (Pearson-r). Factor analysis has confirmed univariate solution of equation. The questionnaire explains $56.88 \%$ variances of severity of depression.

\section{Participants of the Study}

Questionnaires and demographic surveys from 210 freshmen, who were 18 - 28 years old $(M=19.81 ; S D=1.18)$ were collected. The analysis of demographics has shown that $81 \%$ of the subjects were internal students $(n=170)$ while $19 \%$ of them studied externally $(n=40)$. To add, $48.6 \%$ respondents had either a sister or a brother $(n=102)$ while $24.8 \%$ of them had two siblings $(n=52) .19$ subjects $(9 \%)$ had three or more siblings while 37 of them $(17.6 \%)$ were the only children.

The data on participants' perceived financial status are presented on Table 1. They could describe their financial status using the descriptors such as poor, average, good and very good. Also, information on subjects' background and current living arrangements is presented on Table 2, Table 3 and Table 4 respectively.

\section{Procedure for Analysis of Results}

The data were examined in three ways. Firstly, the frequency distribution for the risk of depression was determined, both for each questionnaire item and for the total score (see Table 1). Secondly, the participants were divided into two subgroups in respect to the six points score as an indicator differentiating
Table 1.

Relationships between individual KADS items (Pearson-r).

\begin{tabular}{llllll}
\hline & $\mathbf{1}$ & $\mathbf{2}$ & $\mathbf{3}$ & $\mathbf{4}$ & $\mathbf{5}$ \\
\hline 1. Sadness & - & & & & \\
2. Hopelessness & $.66^{* *}$ & - & & & \\
3. Tiredness & $.47^{* *}$ & $.44^{* *}$ & - & & \\
4. Difficulties of life & $.50^{* *}$ & $.53^{* *}$ & $.51^{* *}$ & - & \\
5. Worry & $.46^{* *}$ & $.50^{* *}$ & $.40^{* *}$ & $.54^{* *}$ & - \\
6. Suicidal thoughts & $.47^{* *}$ & $47^{* *}$ & $.35^{* *}$ & $.48^{* *}$ & $.43^{* *}$ \\
\hline
\end{tabular}

Table 2.

Financial status.

\begin{tabular}{cccccc}
\hline & & Frequency & Percentage & $\begin{array}{c}\text { Valid } \\
\text { percentage }\end{array}$ & $\begin{array}{c}\text { Accumulated } \\
\text { percentage }\end{array}$ \\
\hline \multirow{4}{*}{ Valid } & Bad & 3 & 1.4 & 1.4 & 1.4 \\
& Medium & 69 & 32.9 & 32.9 & 34.3 \\
& Good & 95 & 45.2 & 45.2 & 79.5 \\
& Very good & 43 & 20.5 & 20.5 & 100.0 \\
& Total & 210 & 100.0 & 100.0 & \\
\hline
\end{tabular}

Table 3.

Social background.

\begin{tabular}{|c|c|c|c|c|c|}
\hline & & Frequency & Percentage & $\begin{array}{c}\text { Valid } \\
\text { percentage }\end{array}$ & $\begin{array}{l}\text { Accumulated } \\
\text { percentage }\end{array}$ \\
\hline \multirow{6}{*}{ Valid } & Village & 45 & 21.4 & 21.4 & 21.4 \\
\hline & $\begin{array}{l}\text { City } \\
\text { (population } \\
\text { up to } 30,000 \text { ) }\end{array}$ & 44 & 21.0 & 21.0 & 42.4 \\
\hline & $\begin{array}{l}\text { City (population of } \\
30,000-100,000)\end{array}$ & 39 & 18.6 & 18.6 & 61.0 \\
\hline & $\begin{array}{l}\text { City (population } \\
\text { of } 100,000- \\
300,000 \text { ) }\end{array}$ & 32 & 15.2 & 15.2 & 76.2 \\
\hline & $\begin{array}{l}\text { City (population } \\
\text { of over } 300,000 \\
\text { dwellers) }\end{array}$ & 50 & 23.8 & 23.8 & 100.0 \\
\hline & Total & 210 & 100.0 & 100.0 & \\
\hline
\end{tabular}

Table 4.

Living arrangements.

\begin{tabular}{lcccc}
\hline & Frequency & Percentage & $\begin{array}{c}\text { Valid } \\
\text { percentage }\end{array}$ & $\begin{array}{c}\text { Accumulated } \\
\text { percentage }\end{array}$ \\
\hline $\begin{array}{l}\text { At parent's } \\
\text { home }\end{array}$ & 55 & 26.2 & 26.2 & 26.2 \\
$\begin{array}{l}\text { With } \\
\text { sister/brother }\end{array}$ & 8 & 3.8 & 3.8 & 30.0 \\
$\begin{array}{l}\text { Dormitory } \\
\begin{array}{l}\text { Share a flat } \\
\text { with a }\end{array}\end{array}$ & 24 & 11.4 & 11.4 & 41.4 \\
roommate & 106 & 50.5 & 50.5 & 91.9 \\
$\begin{array}{l}\text { Valid Independent } \\
\text { rent }\end{array}$ & 8 & 3.8 & 3.8 & 95.7 \\
$\begin{array}{l}\text { With family } \\
\text { Rented room } \\
\text { at somebody's }\end{array}$ & 3 & 1.4 & 1.4 & 97.1 \\
flat & .5 & .5 & 97.6 \\
$\begin{array}{l}\text { Own flat } \\
\text { Total }\end{array}$ & 5 & 2.4 & 2.4 & 100.0 \\
\hline
\end{tabular}


between subjects at risk $(n=36 ; 17.1 \%)$ from those not at risk of depression ( $n=174 ; 82.9 \%)$. Additionally, socio-demographic data of the two groups were compared by chi-square test. Next, subjects were separated into subgroups with $(n=18$; $8.6 \%)$ and without suicidal thoughts $(n=192 ; 91.4 \%)$ and then, similarly as before, their socio-demographic data were analyzed by chi-square test.

\section{Results}

\section{Description of the Analyzed Group-Severity of Depression}

The average test score equaled $X=3.20(S D=3.30 ; \mathrm{min}=.00$; $\max =18.00)$. The most frequent symptoms of depression included worry $(n=115 ; 54.8 \%)$ and tiredness $(n=113 ; 53.8 \%)$ whereas suicidal thoughts remained the least frequent symptom whatsoever $(n=18 ; 8.6 \%)$ (Table 5).

The data obtained from respondents were examined in the following way. 1. The participants were divided into two subgroups with respect to the six points score as an indicator differentiating subjects at risk $(n=36 ; 17.1 \%)$ from those not at risk of depression $(n=174 ; 82.9 \%)$. Then, socio-demographic data of the two obtained subgroups were compared by chi-square test. The analysis has not indicated any statistical differences in the investigated demographic parameters (age, gender, background, living arrangements, having brothers or sisters, participant's major and the mode of study) between subjects with and without a risk of depression. In contrast, the study showed statistically significant differences between analyzed subgroups in the perceived financial status. The analysis indicated that students who perceived their financial status as either good or very good were less susceptible to depression than respondents who believed they were poor or participants who thought their financial status was average $\left(\chi^{2}(1)=8.724 ; p<.01\right)$.

2. The subjects were separated into subgroups with $(n=18$; $8.6 \%)$ and without suicidal thoughts $(n=192 ; 91.4 \%)$ and then, as previously, their socio-demographic data were analyzed by chi-square test. As before, out of all investigated determinants only the factor of perceived financial status significantly separated the two groups in question $\left(\chi^{2}(1)=3.953 ; p=.047\right)$. Differences were found between subjects who perceived their financial status as good or very good and respondents who believed they were poor or considered their financial status as average.

Table 5.

Frequency of answers to individual KADS items.

\begin{tabular}{lcccc}
\hline & $\begin{array}{c}\text { Hardly } \\
\text { ever }\end{array}$ & $\begin{array}{c}\text { Much of } \\
\text { the time }\end{array}$ & $\begin{array}{c}\text { Most of } \\
\text { the time }\end{array}$ & $\begin{array}{c}\text { All of } \\
\text { the time }\end{array}$ \\
\hline 1. Sadness & $110(52.4 \%)$ & $69(32.9 \%)$ & $26(12.4 \%)$ & $5(2.4 \%)$ \\
2. Hopelessness & $128(61.0 \%)$ & $62(29.5 \%)$ & $14(6.7 \%)$ & $6(2.9 \%)$ \\
3. Tiredness & $97(46.2 \%)$ & $78(37.1 \%)$ & $30(14.3 \%)$ & $5(2.4 \%)$ \\
4. Difficulties of life & $140(66.7 \%)$ & $51(24.3 \%)$ & $14(6.7 \%)$ & $5(2.4 \%)$ \\
5. Worry & $95(45.2 \%)$ & $85(40.5 \%)$ & $21(10.0 \%)$ & $9(4.3 \%)$ \\
6. Suicidal thoughts & $192(91.4 \%)$ & $12(5.7 \%)$ & $2(1.0 \%)$ & $4(1.9 \%)$ \\
\hline
\end{tabular}

\section{Discussion}

The goal of our study was to evaluate prevalence of depression and suicidal thoughts in first year university students in Poznań, Poland, who came from the province of Great Poland (Wielkopolska) in Midwestern Poland. We also evaluated whether depression and suicidal thoughts were associated with demographic factors such as age or living arrangements. The analysis has shown that as many as $17.1 \%$ of participants were at risk of depression and $8.6 \%$ of them had suicidal thoughts. In the present study, among analyzed factors such as age, having brothers or sisters, background, living arrangements, participant's major and the mode of study, only perceived financial status was significantly associated with susceptibility to depression. Also, we found a similar effect of perceived financial status on suicidal thoughts. This observation confirmed a welldescribed relation between depression and suicidal thoughts [2]. Our results, however, differ from the outcomes of international investigation by Mikolajczyk and colleagues [8], who also indicated an association between income perceived as insufficient and higher levels of depressive symptoms but observed much higher incidence of depressive symptoms ( $40 \%$ of Polish students in Mikolajczyk's the study met the criteria for depression). The Mikolajczyk's group also investigated prevalence of depressive symptoms in students living in Poland (the Lublin province), Denmark, Bulgaria and Germany and compared their results to an earlier study of college students living in the same countries $[19,20]$. With the use of modified version of Beck Depression Inventory (M-BDI) they could observe that susceptibility to depression was higher among students living in former Eastern bloc countries (i.e. $45.5 \%$ and $27.3 \%$ for Polish as compared to $24.9 \%$ and $12.1 \%$ for Danish female and male students respectively). Additionally, they demonstrated that neither political and economic changes in Eastern European countries nor perceived income sufficiency clearly affected differences in the prevalence of depressive symptoms across countries. They concluded that difference in prevalence of depressive symptoms in Eastern (Bulgarian and Polish) and Western European (Danish and German) university students persisted 15 years after political changes had taken place and could not be explained by differences in perceived sufficiency of income [8]. The aforementioned differences between Mikolajczyk's study on depression in students residing in Lublin (40\% after calculation) and the results of our study of students attending universities in Poznan (17.1\%) are so huge that they might not be explained by different tools used in the study (M-BDI versus KADS) or time difference. Also, in the light of Mikolajczyk's study, they should not be attributed to subject's perceived financial status. Yet, it would be valuable to consider the influence of environmental factors, culture, tradition and socio-economic status [17]. Great Poland is significantly wealthier and much better economically developed then the region of Lublin, where the Mikolajczyk's study was carried out. Lublin is located in an unprivileged area of Poland which is in need of special European funds to help it grow. It is often called second-class Poland (Poland B). Nevertheless, this argument becomes doubtful in view of a study of Turkish students in Denizli. Despite cultural, social and religious differences, their results were similar to ours [9].

The analysis of agents influencing depression should take into consideration other determinants such as the fact that students are a specific group of people who want to climb up on a 
social ladder. To be accepted to university they have to pass necessary examinations and compete with their peers. The process of admission to the university not only entails preparation and continuous effort to maintain one's student status but is also very stressful. Also, there may be local differences in student's aspiration to complete university education. Perhaps for young people in Lublin the ambition to become a student is more stressful than for youth living in the Wielkopolska region, who have a wider access to education at university level. The effect of one's aspiration to complete university education could to some extent be supported by publications devoted to medical students, in whom depressive symptoms were linked to stress accompanying becoming a medical doctor (e.g. increasing workload, level of academic pressure, inadequate social life and resulting low perceived interpersonal social support) $[21,24,25]$. However, further research of the presented suggestion is necessary.

\section{REFERENCES}

Beautrais, A. L. (2010). Risk factors for suicide and attempted suicide among young people. Australian and New Zealand Journal of Psychiatry, 34, 420-436. doi:10.1080/j.1440-1614.2000.00691.x

Cash, S. J., \& Bridge, J. A. (2009). Epidemiology of youth suicide and suicidal behavior. Current Opinion in Pediatrics, 21, 613-619. doi:10.1097/MOP.0b013e32833063e1

Szumilas, M., \& Kutcher, S. P. (2008). Youth and suicide. CMAJ fact sheet. Canadian Medical Association Journal, 178, 286. doi:10.1503/cmaj.071559

Verona, E., \& Javdani, S. (in press). Dimensions of adolescent psychopathology and relationships to suicide risk indicators. Journal of Youth and Adolescence.

Polewka, A., Kroch, S., \& Chrostek, M. J. (2004). Suicidal behavior and suicide attemptsin adolescents and young adults-Epidemiology, risk factors, prevention and treatment. Przegl Lek, 6, 261-264.

LeBlanc, J. C., Almudevar, A., Brooks, S. J., \& Kutcher, S. (2002). Screening for adolescent depression: Comparison of the Kutcher adolescent depression scale with the beck depression inventory. Journal of Child and Adolescent Psychopharmacology, 12, 113-126. doi: $10.1089 / 104454602760219153$

Beck, A. T., Steer, R. A., Ball, R., \& Ranieri, W. (1996). Comparison of beck depression inventories-IA and -II in psychiatric outpatients. Journal of Personality Assessment, 67, 588-597. doi:10.1207/s15327752jpa6703_13

Mikolajczyk, R. T., Maxwell, A. E., El Ansari, W., Naydenova, V., Stock, C., Ilieva, S., Dudziak, U., \& Nagyova, I. (2008). Prevalence of depressive symptoms in university students from Germany, Denmark, Poland and Bulgaria. Social Psychiatry and Psychiatric Epidemiology, 43, 105-112. doi:10.1007/s00127-007-0282-0

Bostanci, M., Ozdel, O., Oguzhanoglu, N. K., Ozdel, L., Ergin, A., Ergin, N., Atesci, F., \& Karadag, F. (2005). Depressive symptomatology among university students in Denizli, Turkey: Prevalence and sociodemographic correlates. Croatian Medical Journal, 46, 96-100.
Goodyer, I. M., Herbert, J., Tamplin, A., \& Altham, P. M. E. (2000). First-episode major depression in adolescents: Affective, cognitive and endocrine characteristics of risk status and predictors of onset. The British Journal of Psychiatry, 176, 142-149. doi:10.1192/bjp.176.2.142

Ustun, T. B., \& Kessler, R. C. (2002). Global burden of depressive disorders: The issue of duration. The British Journal of Psychiatry, 181, 181-183. doi:10.1192/bjp.181.3.181

Keller, M. C., Neale, M. C., \& Kendler, K. S. (2007). Association of different adverse life events with distinct patterns of depressive symptoms. American Journal of Psychiatry, 164, 1521-1529. doi:10.1176/appi.ajp.2007.06091564

Fergusson, D. M., Boden, J. M. \& Horwood, L. J. (2007). Recurrence of major depression in adolescence and early adulthood, and later mental health, educational and economic outcomes. The British Journal of Psychiatry, 191, 335-342. doi:10.1192/bjp.bp.107.036079

Tjia, J., Givens, J. L., \& Shea, J. A. (2005). Factors associated with undertreatment of medical student depression. The Journal of American College Health, 53, 219-224. doi:10.3200/JACH.53.5.219-224

Mendelson, T., Kubzansky, L. D., Datta, G. D., \& Buka, S. L. (2008). Relation of female gender and low socioeconomic status to internalizing symptoms among adolescents: A case of double jeopardy? Social Science \& Medicine, 66, 1284-1296. doi:10.1016/j.socscimed.2007.11.033

Wardle, J., Steptoe, A., Gulis, G., Sartory, G., Sek, H., Todorova, I., Vogele, C., \& Ziarko, M. (2004). Depression, perceived control, and life satisfaction in university students from Central-Eastern and Western Europe. International Journal of Behavioral Medicine, 11, 27-36. doi:10.1207/s15327558ijbm1101 4

Goodman, E., Huang, B., Wade, T. J., \& K Kahn, R. S. (2003). A multilevel analysis of the relation of socioeconomic status to adolescent depressive symptoms: Does school context matter? Journal of Pediatrics, 143, 451-456. doi:10.1067/S0022-3476(03)00456-6

Lorant, V., Deliege, D., Eaton, W., Robert, A., Philippot, P., \& Ansseau, M. (2003). Socioeconomic inequalities in depression: A meta-analysis. American Journal of Epidemiology, 157, 98-112. doi:10.1093/aje/kwf182

Jeong, Y., Kim, J. Y., Ryu, J. S., Lee, K. E., Ha, E. H., \& Park, H. (2010). The Associations between social support, health-related behaviors, socioeconomic status and depression in medical students. Epidemiology and Health, 32, 1-8. doi:10.4178/epih/e2010009

Li, Y., \& Sato, Y. (2008). Relationship between socioeconomic factors, health behaviors, and mental health among university students of Heilongjiang province in China. School Health, 4, 9-15.

Lorant, V., Deliege, D., Eaton, W., Robert, A., Philippot, P., \& Ansseau, M. (2003). Socioeconomic inequalities in depression: A metaanalysis. American Journal of Epidemiology, 157, 98-112. doi:10.1093/aje/kwf182

Sahraian, A., \& Javadpour, A. (2010). Sleep disruption and its correlation to psychological distress among medical students. Shiraz $E$ Medical Journal, 11, 12-17.

Inam, S. N., Saqib, A., \& Alam, E. (2003). Prevalence of anxiety and depression among medical students of private university. Journal of the Pakistan Medical Association, 53, 44-47. 